\title{
Clinical, light, and electron microscopy findings in idiopathic haematuria ${ }^{1}$
}

\author{
F. ALEXANDER, R. LANNIGAN, AND R. BULL \\ From the Division of Pathology, Faculty of Medicine, The University of Calgary, \\ Calgary, Alberta, Canada
}

SYNOPSIS The electron microscopic findings are reported in detail in 20 patients submitted to renalo biopsy with the major complaint or clinical finding of gross or microscopic haematuria. The lesions were classified histologically into four groups: group 1, minor glomerular alterations; group $2, \frac{\circ}{\circ}$ focal mesangial thickening and/or cellular proliferation; group 3, diffuse mesangial proliferation; and group 4, other lesions. The major ultrastructural alterations included irregularity in thickness and density of the capillary basement membrane, with apparent discontinuity and bi- or multi-을 laminar splitting of the lamina densa. There were varying degrees of foot process fusion, visceral $\overrightarrow{-}$ epithelial polykaryocytosis, and granular deposits related to the capillary basement membrane. Densities were found in the mesangial basement membrane-like material, which was often markedly음 increased in quantity. A few microtubular aggregates were observed in endothelial cell cytoplasm. ㄴ. Changes consistent with acute diffuse proliferative and membrano-proliferative glomerulonephritis $\overrightarrow{0}$ were also seen. The significant clinical findings, histological groups, and ultrastructural changes age correlated.

Persistent, recurrent, and symptomless haematuria remains a diagnostic problem for the clinician. In the elderly patient this is generally related to a lesion of the urinary tract, sometimes neoplastic in nature. In the younger patient, however, urological investigations are frequently negative and the lesion is clinically labelled 'focal' glomerulonephritis, especially if the onset of haematuria is related to an episode of upper respiratory tract infection. If deafness or ocular abnormalities are associated with the haematuria, investigations of siblings and relatives may disclose a familial disorder of uncertain genetic make-up (Alport, 1927; Grace, Suki, Spjut, Eknoyan, and Martinez-Maldonado, 1970). The pathological changes in patients with primary or symptomless haematuria have been graded by Glasgow, Moncrieff, and White (1970) and Hendler, Kashgarian, and Hayslett (1972), on the basis of light microscopic changes. The former found only two of 47 patients to have significant glomerular disease, whilst the latter reported 18 cases of diffuse proliferative glomerulonephritis, seven cases of chronic glomerulonephritis, and two with acute proliferative and exudative

${ }^{1}$ This investigation was supported in part by grant MA-4551 from the Medical Research Council of Canada.

Received for publication 16 July 1973. glomerulonephritis. Seymour, Spargo, and Penska (1971) found the changes in renal biopsies from $\frac{\varnothing}{\varnothing}$ patients with asymptomatic haematuria to be often $\cong$ subtle and only visible with electron microscopy, and $\overrightarrow{\overrightarrow{0}}$ Burkholder, Dotin, Thomason, and Beach (1969), 3 found normal renal biopsy on light microscopy in nine cases of unexplained haematuria. Relatively? little has been reported on the ultrastructural changes in the glomeruli in this condition. The purpose of this report is to document ultrastructural lesions 3 observed in the glomeruli of these patients, whose major complaint or physical finding was gross or microscopic haematuria, in the absence of any 0 urinary tract abnormality, and to compare the light and electron microscopy and clinical findings. These $\frac{D}{2}$ cases have accounted for approximately $10 \%$ of renal biopsies performed here during the past two 0 years.

\section{Materials and Methods}

The 20 patients reviewed here were all submitted to renal biopsy because of haematuria, either of a gross nature causing the patient to consult his practitioner or microscopic when it was discovered on routine $\frac{0}{0}$ examination. All but one of the patients had recurrent $\frac{\mathrm{O}}{\mathrm{D}}$ haematuria before biopsy for periods varying from $\stackrel{\overrightarrow{\mathrm{D}}}{\mathrm{Q}}$ 
two months to 12 years. Eight patients had red cell casts on at least one occasion and eight gave a history of upper respiratory tract infection associated with some of the episodes of haematuria. The patients' ages ranged from 7 to 56 years at the time of onset or diagnosis of haematuria. Selection of patients was influenced by the policy at this centre of not performing renal biopsy on young children with haematuria only. The clinical investigation was not uniform throughout the group as they were referred from several centres, but renal or urinary tract neoplasms, renal calculi, hydronephrosis, and chronic urinary tract infections were excluded by intravenous pyelography and cystoscopy. None of the patients was hypertensive; there was no subcutaneous oedema and blood urea nitrogen and serum creatinine levels were normal, when performed. Before kidney biopsy all patients were screened for a possible bleeding disorder and none was found. Renal biopsy was performed by percutaneous or open method and the specimens obtained were prepared for light and electron microscopy. For the former, the tissue was fixed in $10 \%$ formol-saline, paraffin embedded, and sectioned at 2 to $3 \mu$. Sections were stained with haematoxylin and eosin (H \& E), periodic acid-Schiff (PAS), and periodic acid-silver methenamine (PASM). The tissue for electron microscopy was fixed in $5 \%$ glutaraldehyde, postfixed in osmium tetroxide, embedded in Epon, sectioned and stained with uranyl acetate and lead citrate, and examined in a Philips $\mathbf{3 0 0}$ or AEI Corinth 275 microscope.

The light microscopy findings were classified into four groups: group 1, minor glomerular alterations; group 2, focal mesangial thickening and/or proliferation; group 3, diffuse mesangial thickening and proliferation; group 4, other lesions.

\section{Results}

\section{LIGHT MICROSCOPY}

\section{Group 1 (four patients)}

Most of the glomeruli appeared normal, though occasionally some thickening of the mesangial region was suggested by $\mathrm{H} \& \mathrm{E}$ staining and confirmed by PAS and PASM staining.

\section{Group 2 (12 patients)}

The majority of the glomeruli showed some areas of increase in PAS and PASM positive material in the mesangial region and a focal increase in the number of mesangial cells.

\section{Group 3 (one patient)}

There was a diffuse increase in mesangial cellularity $2^{*}$ and PAS- and PASM-staining material within the mesangial region.

\section{Group 4 (three patients)}

Two of these patients showed features characteristic of membrano-proliferative glomerulonephritis with diffuse mesangial proliferation of PAS- and PASMstaining material and cells, and marked thickening of the capillary wall, often with duplication of the basement membrane as seen with PASM staining. One patient showed acute diffuse proliferation of all preexisting glomerular elements and occasional polymorphs, typical of acute diffuse proliferative glomerulonephritis. This was the only patient seen during the first known attack of haematuria.

One patient (case 9) had two biopsies, the first in 1966 showing only minor mesangial thickening corresponding to group 1 . Two years later there was diffuse mesangial thickening of moderate degree generally and quite severe in a few glomeruli with associated mesangial hypercellularity. This lesion was considered to have progressed from group 1 to group 2 over the period of two years.

\section{ELECTRON MICROSCOPY (16 CASES)}

\section{Group 1}

Few ultrastructural alterations were observed in this group.

Some increase in thickness was observed focally on the endothelial aspect of the basement membrane in two cases. This thickened area was electron pale. One case demonstrated focal splitting of the lamina densa with intervening pallor. There was an increase in basement-membrane-like material in the mesangial areas of two cases. Epithelial cell cytoplasm appeared swollen with numerous cytoplasmic inclusions and prominent endoplasmic reticulum. Vacuoles were observed in the endothelial cells.

\section{Group 2}

The changes here were much more striking than in group 1. Irregularity in thickness of the capillary basement membrane was observed to be due to focal increase in the quantity of electron-pale material on the endothelial aspect of the lamina densa in seven cases and to focal thinning of the total membrane in five cases, this being extremely marked in two cases (fig 1). No definite complete breach of the basement membrane was seen, but in a very few areas it was reduced severely, at one point to a mere filament$400 \AA$ thick (fig 2). Three cases showed splitting of the lamina densa of the basement membrane into two or more layers with intervening pale zones.

Electron-dense deposits of granular appearance were present in seven cases. In five cases they were 


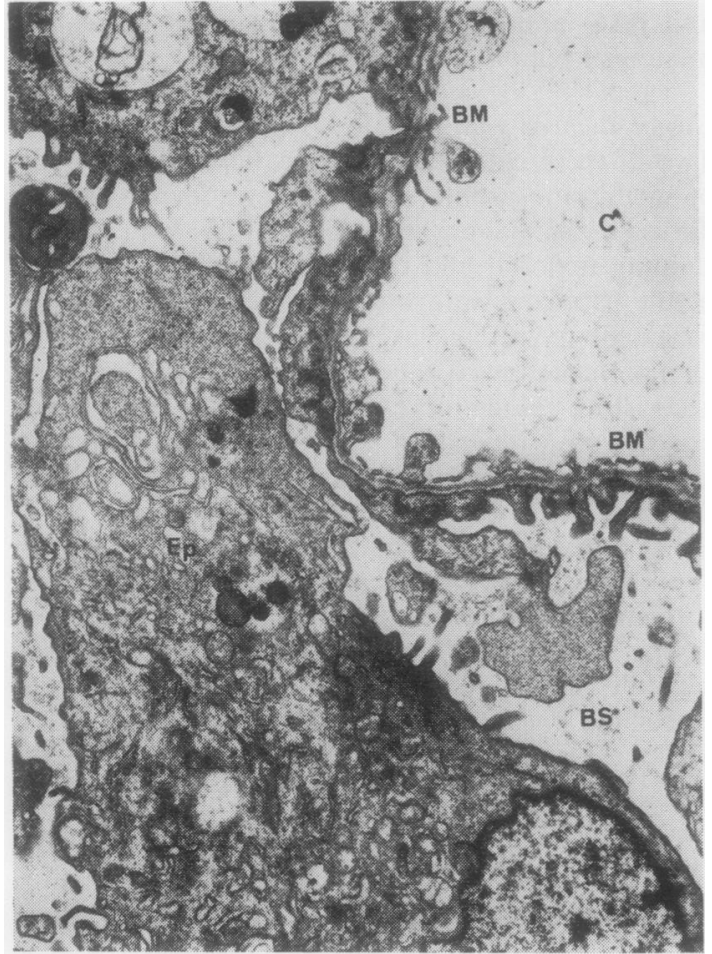

Fig 1

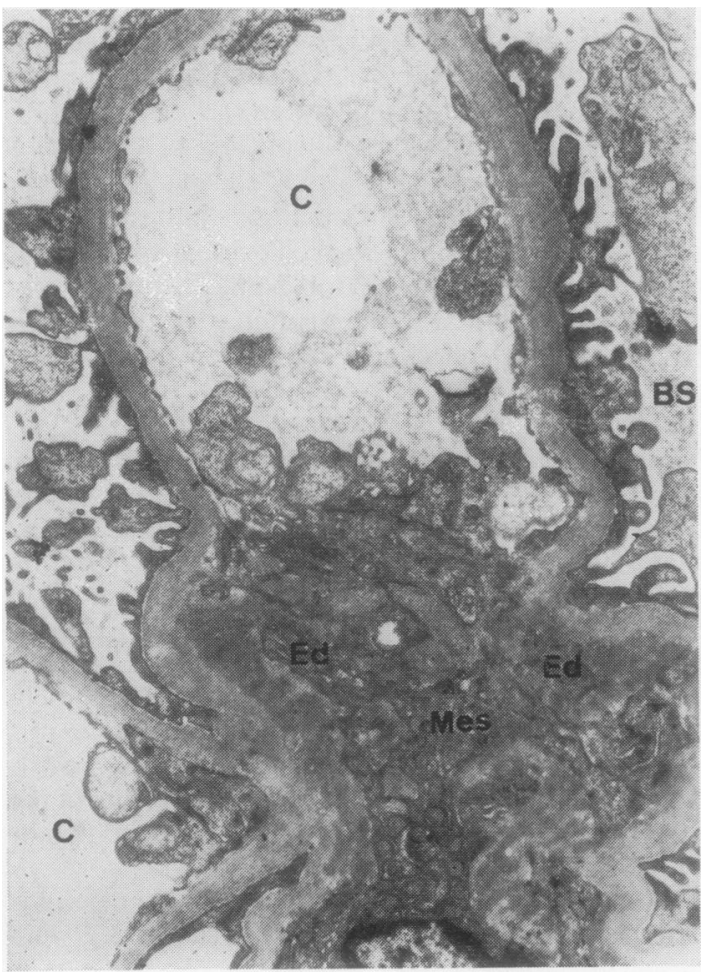

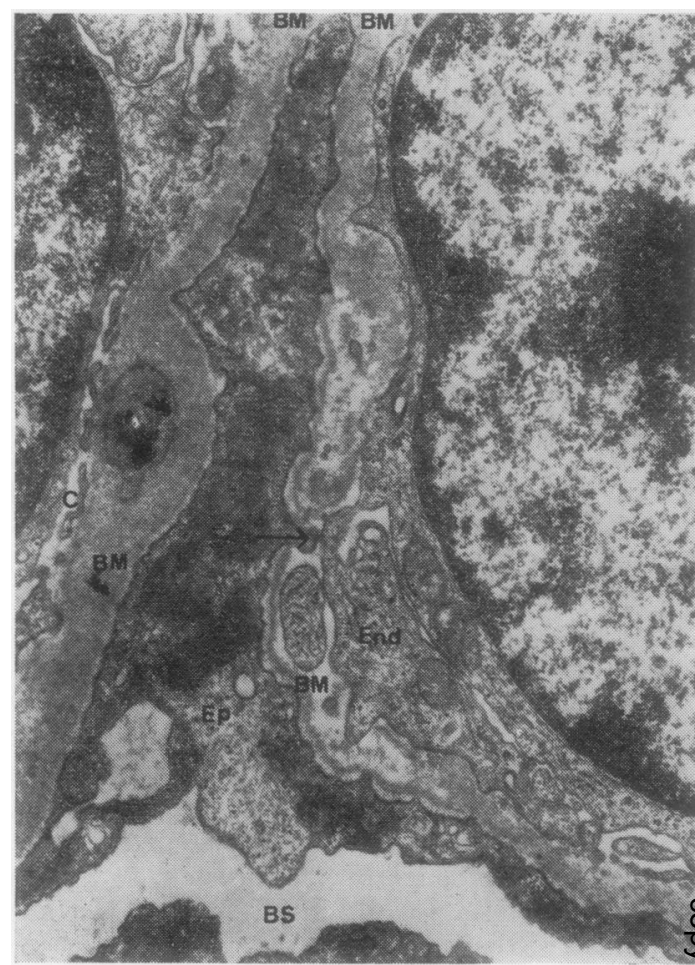

Fig 2

Fig 1 The basement membrane (BM) is extremely thin over the capillary loop (C). Epithelial cell foot processes are partly fused over the area where the structure of the membrane is indistinct. Normal BM thickness $2000 A^{\circ}-35000 A^{\circ} . \times 14000$.

Fig 2 The capillary basement membrane (BM) shows irregularity, pallor, and extreme narrowing $(\rightarrow)$ to approximately $400 \mathrm{~A}^{\circ} . \times 25600$.

Fig 3 Electron-dense areas (Ed) are noted in the mesangium (Mes) and on the mesangial side of the overlying basement membrane. $\times 8550$. 


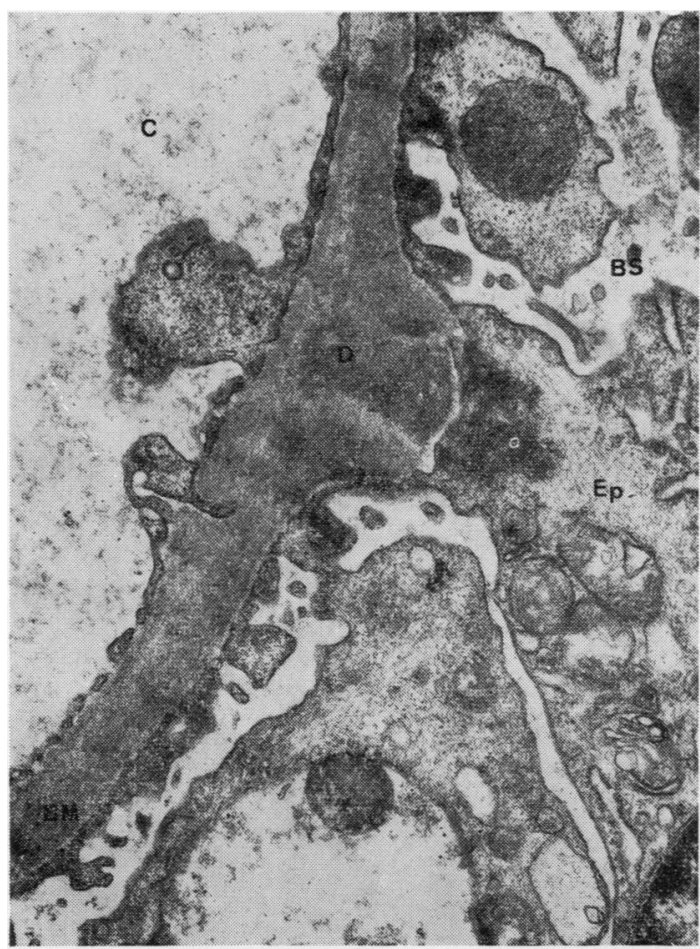

Fig 4

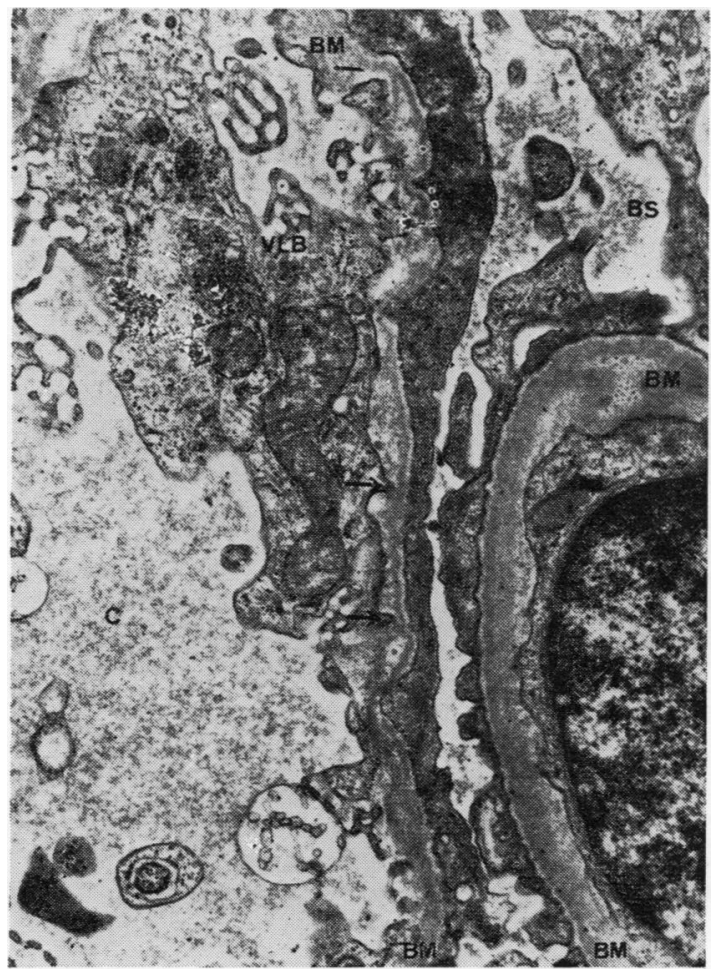

Fig 6

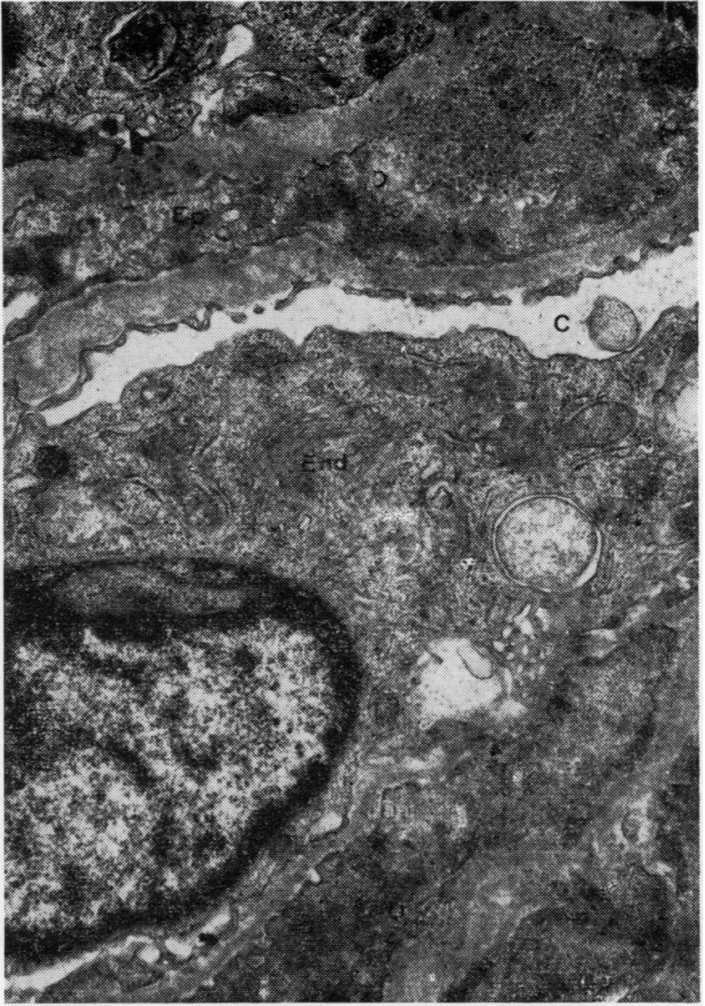

Fig 5

Fig 4 A granular density (D) is present in the basement membrane, extending towards the epithelial (Ep) aspect. The adjacent epithelial cell cytoplasm also shows marked electron dense granularity. $\times 25600$.

Fig 5 Areas of very coarse open granularity (D) project on the epithelial side of the basement membrane. $\times 18240$.

Fig 6 Microtubular structures-virus-like bodies (VLB) are noted in the endothelial cell cytoplasm. The basement membrane is very irregular in contour and densitythinned to approximately $1500 A^{\circ}(\rightarrow) \times 21000$. 
observed in the mesangial region (fig 3), and in one they were also found in Bowman's capsule. Mesangial and poorly formed subendothelial deposits were noted in three cases and subepithelial deposits were seen in three. Only one case demonstrated a single area of dense granularity within the membrane and extending towards the epithelial aspect (fig 4). Granular electron-dense material was observed in the overlying epithelial cell cytoplasm. The deposits on the extreme epithelial aspect of the membrane were of a much coarser granularity than elsewhere (fig 5).

Mesangial proliferation of basement-membranelike material was a common finding, but hypercellularity was seen in the mesangial region in only two cases. There was an abundance of cytoplasmic organelles including myelin figures in the epithelial cells of several patients, and one demonstrated several binucleated epithelial cells-polykaryocytosis.
Foot process loss was a constant feature, but only of $\stackrel{0}{=}$ a very focal nature and related to membrane $\underline{\sigma}$ abnormalities or deposits. Occasionally endothelial cell swelling and vacuolation was observed. Microtubular structures were present in the endothelialo cell cytoplasm of one case (fig 6 ).

\section{Group 3}

Only one patient fell into this category. The basement membrane was variable in thickness with extreme ${ }_{-}$ irregularity of both epithelial and endothelial aspects. of the basement membrane and marked focal pallor. $\vec{\omega}$ Splitting of the lamina densa was very marked in one glomerulus and absent in another. Areas of granular:응 density were incorporated between the layers of thein split lamina densa over some capillary loops (fig 7). One small focus of coarse granular deposit was noted $\vec{\circ}$ on the inner aspect of the basement membrane and aN

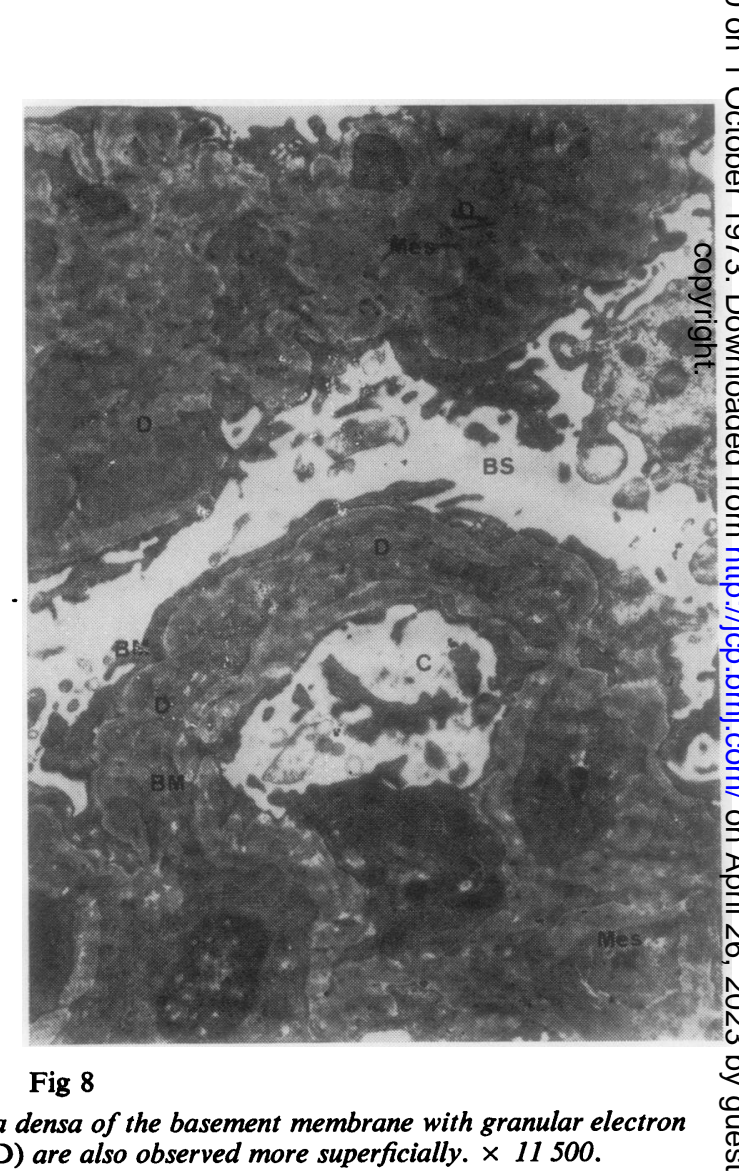

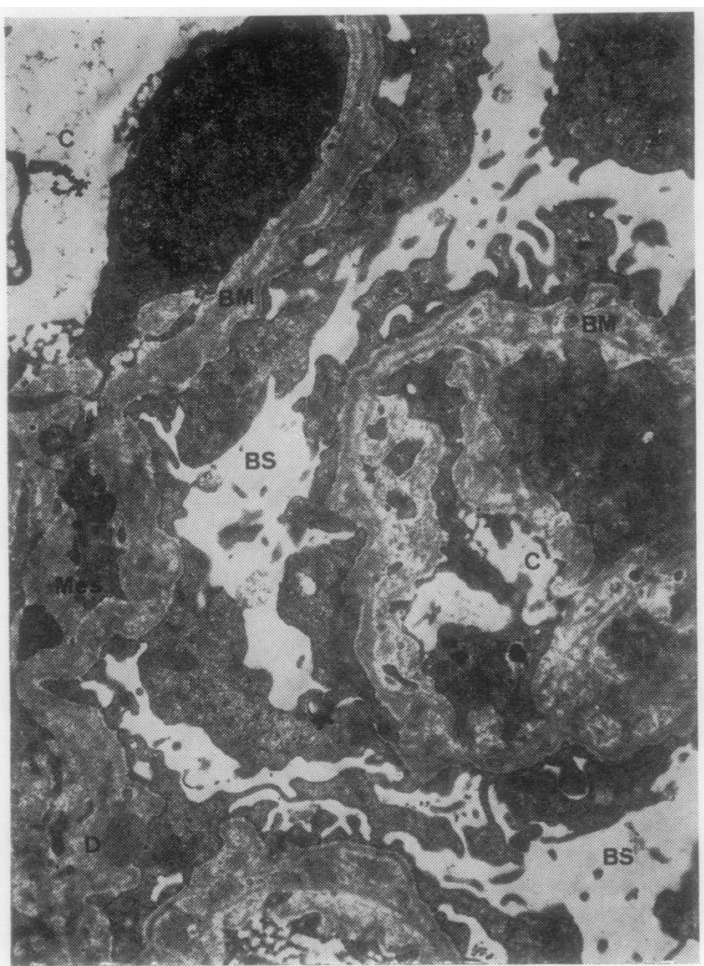

Fig 7

Fig 7 Very marked splitting and irregularity of the lamina densa of the basement membrane with granular electron densities diffusely dispersed between the layers. Densities (D) are also observed more superficially. $\times 11500$.

Fig 8 Two basement membranes surround a capillary loop $C$, with mesangial cell cytoplasm between them. Deposits (D) are noted on the inner aspect of the outer or true membrane. Numerous dense areas are also present in the mesangium where there is a marked increase in basement membrane-like material. Foot processes are fused over the capillary basement membrane. $\times 9800$. 


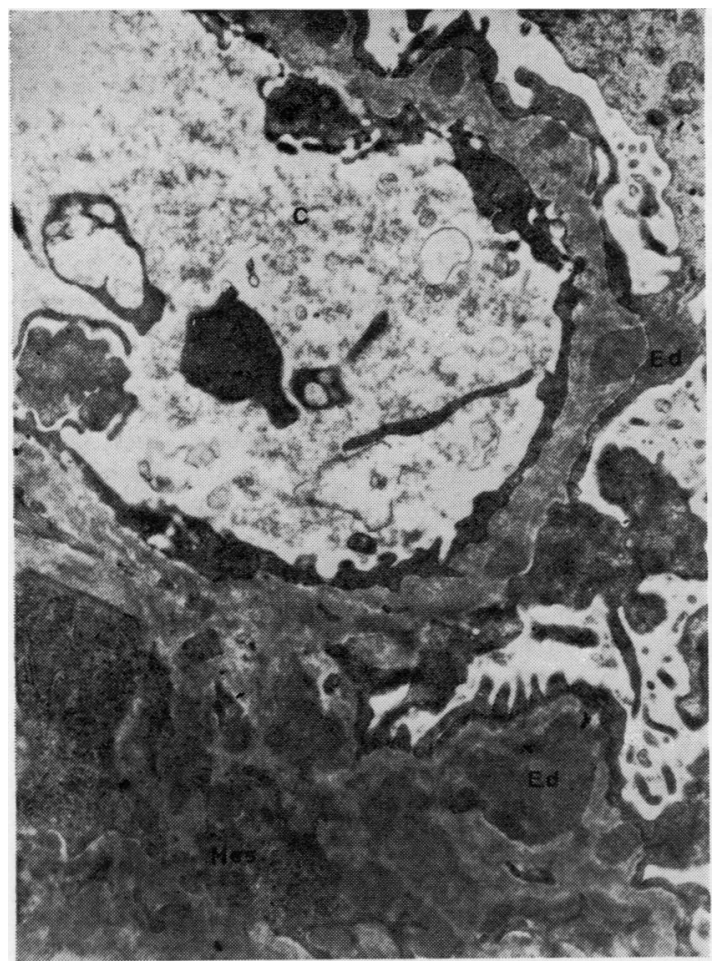

Fig 9

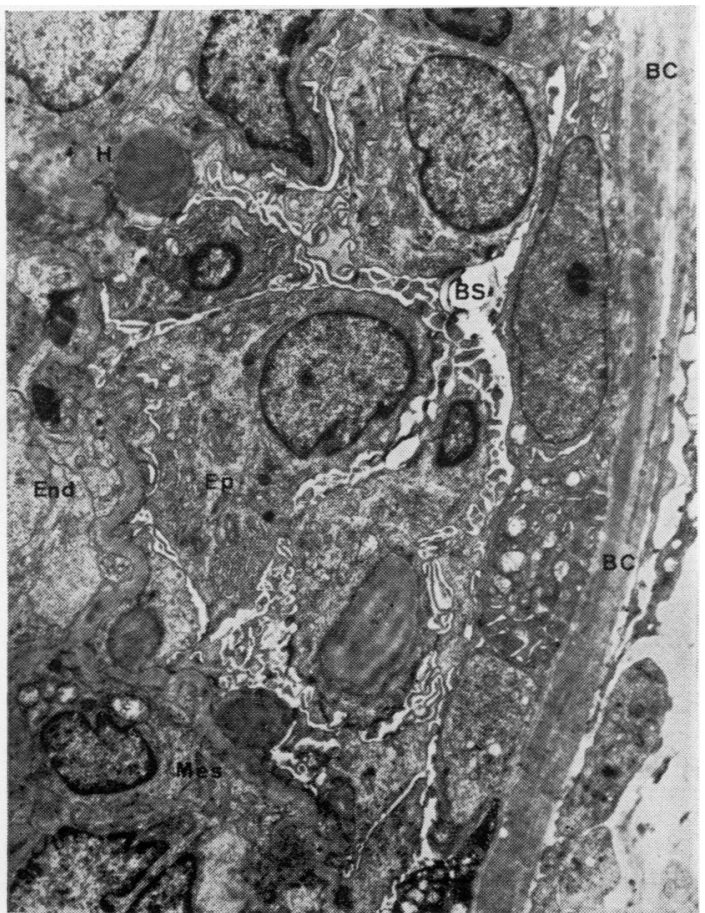

Fig 11

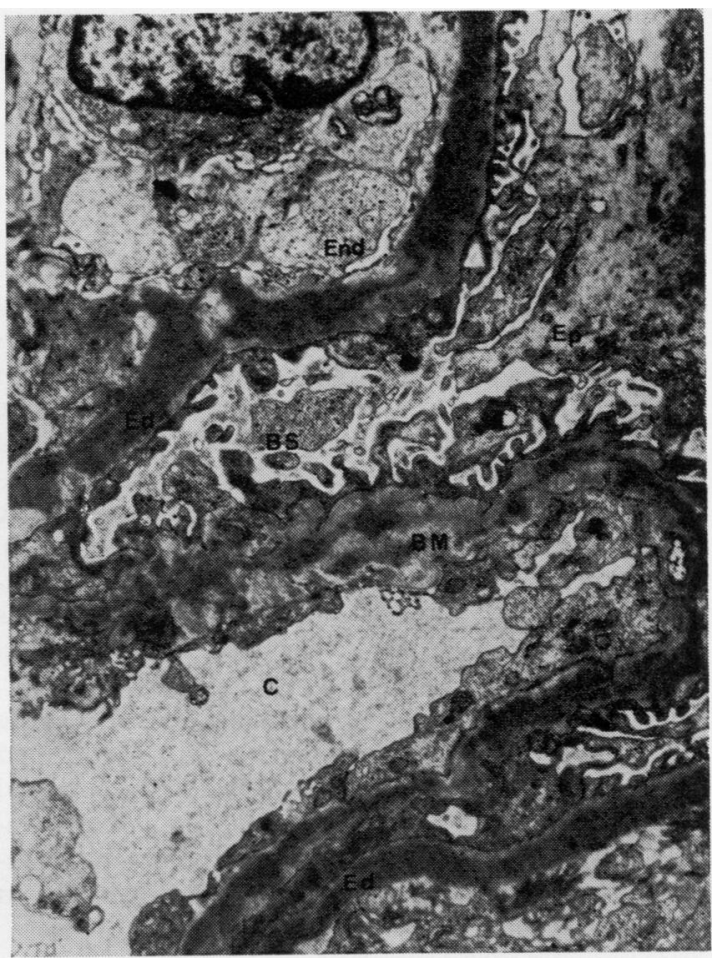

Fig 10

Fig 9 Electron densities (Ed) are located on the epithelial side of the capillary basement membrane, with outward extension of the membrane as in epimembranous nephropathy. Similar densities are located in the mesangium. $\times 20000$.

Fig 10 Irregular diffuse deposition of electron-dense material is spread throughout the basement membrane, which is of very variable dimensions. $\times 14000$.

Fig 11 Epithelial, endothelial, and mesangial cell proliferation are combined with electron-dense 'humps' (H). Electron-dense areas are also scattered in Bowman's capsule (BC). $\times 10000$. 
rare large deposit was present on the epithelial side. Focal mesangial proliferation of basement-membrane-like material and cells was observed.

\section{Group 4}

This diverse group showed features characteristic of the light microscope diagnosis.

The double membrane formation with interposed mesangial cell cytoplasm of membrano-proliferative glomerulonephritis or capillary mesangial interposition was accompanied by electron-dense deposits on the inner aspect of the outer or true membrane (fig 8). Over capillaries without double layers of membrane some deposits were located on the epithelial aspect with associated basement membrane thickening as in epimembranous nephropathy (fig 9). Granular densities were also observed in the mesangium. In some capillary loops the membrane was diffusely and irregularly involved with marked accumulations of granular dense material (fig 10).

The light microscope diagnosis of acute diffuse proliferative glomerulonephritis was confirmed ultrastructurally by finding epithelial, endothelial and mesangial cell proliferation. Numerous electrondense 'humps' were present on the basement membrane and there were long granular densities in several areas of Bowman's capsule (fig 11).

\section{Discussion}

Considerable confusion has arisen over the use of the term 'focal glomerulonephritis' by clinicians and pathologists. The clinical term in its original form (Volhard and Fahr, 1914) relates to a symptom complex of haematuria associated with an attack of upper respiratory tract infection. It has more recently come into common usage for recurrent or symptomless haematuria with or without evidence of associated upper respiratory tract infection. 'Focal glomerulonephritis' in a pathological sense, however, refers only to the anatomical distribution of glomerular disease and may occur not only in patients with haematuria, as seen here, but with a wide variety of disorders, including polyarteritis nodosa, HenochSchoenlein purpura, systemic lupus erythematosus (Heptinstall and Joekes, 1959; McCluskey, 1970), Goodpasture's syndrome (Benoit, Rulon, Theil, Doolan, and Watten, 1964), nephrotic syndrome (Habib and Kleinknecht, 1971), and subacute bacterial endocarditis (Heptinstall, 1966). It is clear that the two modes of usage are incompatible with clear interpretation, but despite pleas from Lannigan and Insley (1965), Glasgow et al (1970), and Hendler et al (1972), old habits appear to die hard. It would seem that one of the terms 'symptomless', 'persistent', or 'recurrent' could be used clinically leaving morphological terminology to the morphologists, or the lesion may be referred to as essential haematurias since the aetiology is unknown. Arguments have already been raised against the others as no one ofe them adequately describes the various possible presentations.

The clinical, light, and electron microscopy findings are shown in table I. The patients for this study

\begin{tabular}{|c|c|c|c|c|c|c|c|c|c|c|c|c|c|c|c|}
\hline \multirow{2}{*}{$\begin{array}{l}\text { Case } \\
\text { No. }\end{array}$} & \multirow{2}{*}{$\begin{array}{l}\text { Age } \\
\text { (yr) at } \\
\text { Onset }\end{array}$} & \multirow{2}{*}{ Sex } & \multirow{2}{*}{$\begin{array}{l}H / o \\
\text { URTI }\end{array}$} & \multirow{2}{*}{$\begin{array}{l}\text { Dura- } \\
\text { tion }(y r) \\
\text { of } \\
\text { Haema- } \\
\text { turia }\end{array}$} & \multirow{2}{*}{$\begin{array}{l}\text { Degree } \\
\text { of } \\
\text { Haema- } \\
\text { turia }\end{array}$} & \multicolumn{2}{|c|}{ Proteinuria } & \multirow{2}{*}{$\begin{array}{l}\text { Histo- } \\
\text { logical } \\
\text { Group }\end{array}$} & \multicolumn{2}{|c|}{ Basement Membrane } & \multicolumn{2}{|l|}{ Mesangium } & \multirow{2}{*}{\multicolumn{2}{|c|}{$\begin{array}{l}\text { Deposits Poly- } \\
\text { in Bow- karyo- } \\
\text { man's cytosis } \\
\text { Capsule }\end{array}$}} & \multirow{2}{*}{$\begin{array}{l}\text { Tubu } \\
\text { Aggr } \\
\text { gates }\end{array}$} \\
\hline & & & & & & $\begin{array}{l}<0 \cdot 5 \\
g / 24 h r\end{array}$ & $\begin{array}{l}>0.5 \\
g / h r 24\end{array}$ & & $\begin{array}{l}\text { Uneven Split- } \\
\text { Thick- ting } \\
\text { ness }\end{array}$ & $\begin{array}{l}\text { Dupli- Deposits } \\
\text { cation }\end{array}$ & $\begin{array}{c}\text { Sclerosis Hyper- } \\
\text { cellu- } \\
\text { larity }\end{array}$ & Deposits & & & \\
\hline
\end{tabular}

\begin{tabular}{|c|c|c|c|c|c|c|c|c|c|c|c|c|c|c|c|c|c|c|}
\hline 1 & 9 & $\mathbf{F}$ & + & 6 & Micro & + & & 1 & + & + & & & + & & & & & \\
\hline 2 & 18 & $\mathbf{M}$ & & $3 / 12$ & Gross & + & & 1 & + & & & & & & & & & \\
\hline 3 & 5 & $\mathbf{M}$ & + & 10 & Gross & + & & 1 & & & & & & & & & & \\
\hline 4 & 23 & $\mathrm{~F}$ & & & Micro & + & & 1 & & & & & + & & & & & \\
\hline 5 & 15 & $\mathbf{M}$ & & $2 / 12$ & Micro & + & & 2 & + & & & + & & & + & & & \\
\hline 6 & 9 & $\mathbf{M}$ & & & Gross & & $\div$ & 2 & & + & & + & & + & & & & \\
\hline 7 & 29 & $F$ & + & 3 & Gross & & + & 2 & + & + & & + & & & + & & & + \\
\hline 8 & 28 & $F$ & + & $3 / 12$ & Gross & + & & 2 & + & & & & + & & & & & \\
\hline 9 & 16 & $\mathrm{~F}$ & & 2 & Gross & & $\longleftarrow$ & $1 \rightarrow 2$ & & & & & & & & & & \\
\hline 10 & 12 & $\mathbf{M}$ & & $6 / 12$ & Micro & + & & 2 & & & & + & & & + & & + & \\
\hline 11 & 23 & $\mathbf{M}$ & + & 10 & Gross & + & & 2 & & & & & & & & & & \\
\hline 12 & 43 & $F$ & & $5 / 12$ & Micro & + & & 2 & + & & & & $+r$ & & + & & & \\
\hline 13 & 26 & $\mathbf{M}$ & & $2 / 12$ & Gross & & $\longrightarrow$ & 2 & + & & & & & & & + & & \\
\hline 14 & 17 & $\mathrm{~F}$ & & $6 / 12$ & Gross & & + & 2 & & & & & & & & & & \\
\hline 15 & 56 & $\mathbf{M}$ & & $3 / 12$ & Gross & & + & 2 & + & & & + & + & & + & & & \\
\hline 16 & 9 & $\mathbf{M}$ & & & Gross & & + & 2 & + & + & & & + & + & & & & \\
\hline 17 & 23 & $\mathbf{M}$ & + & $26 / 12$ & Gross & & + & 3 & + & + & & + & + & + & + & & & \\
\hline 18 & 11 & $\mathbf{F}$ & + & $12 / 12$ & Gross & & $\longrightarrow$ & 4 & & & + & + & + & + & + & & & \\
\hline 19 & 11 & $\mathbf{M}$ & + & 2 & Gross & & + & 4 & + & + & + & + & + & & + & & & \\
\hline 20 & 7 & $F$ & & - & Gross & & + & 4 & & & & + & & + & + & + & & \\
\hline
\end{tabular}


were selected on the basis of the clinical indication for renal biopsy, namely, haematuria. This had been recurrent in all but one, in whom the biopsy was performed very soon after presentation for diagnosis of the cause of haematuria in this 7-year-old female. There was no history or evidence of upper respiratory tract infection. Haematuria was marked and there were red cell casts and protein in the urine. No radiological evidence of urinary tract abnormality was found. This case therefore would not fit into a classification of recurrent or persistent haematuria, but certainly fulfils the criteria for symptomless haematuria. The renal biopsy findings were those of acute diffuse proliferative glomerulonephritis with ultrastructural evidence of 'humps'. This finding is of particular interest in relation to the absence of any sore throat or skin lesion, no streptococcus isolated from the pharynx, and no elevation of antistreptolysin 0 titre. The complement level first done 10 days after biopsy ranged from 60 to 95 units over a period of three weeks. Are 'humps' diagnostic of acute poststreptococcal glomerulonephritis?Kimmelstiel, Kim, and Beres (1962) originally considered it tempting to look at them as pathognomonic for glomerulonephritis, but Herdson, Jennings, and Earle (1966) have suggested that with the possible exceptions of serum sickness and poststreptococcal exacerbations of chronic glomerulonephritis 'humps' may be pathognomonic of acute poststreptococcal disease.

Since the time of biopsy one year ago this patient has continued to have proteinuria and microscopic haematuria with no evidence of renal functional impairment.

Of the four patients in group 1, two had gross haematuria, one at regular intervals over a period of 10 years. In this case the haematuria was first discovered when the patient was in hospital for a tonsillectomy after repeated attacks of sore throat. A streptococcal aetiology was not documented. A second patient also gave a history of upper respiratory tract infection. Proteinuria was light in all four, the heaviest recorded level being $30 \mathrm{mg} \%$ on one occasion in one patient.

In group 2 (12 patients), nine had gross haematuria and red cell casts were recorded in three. Three of these patients had a definite association between upper respiratory tract infections and episodes of haematuria and one had an elevated antistreptolysin 0 titre with a history suggestive of previous acute glomerulonephritis. Proteinuria at the last determination was more than $0.5 \mathrm{~g} / 24 \mathrm{hr}$ in five patients, the highest level recorded being $1.3 \mathrm{~g} / 24 \mathrm{hr}$ in one patient. In one patient the level of proteinuria rose from $0.2 \mathrm{~g} / 24 \mathrm{hr}$ at the onset of haematuria to $0.9 \mathrm{~g} / 24 \mathrm{hr}$ two months later. In another it fell from a level of
$2.4 \mathrm{~g} / 24 \mathrm{hr}$ to $0.1 \mathrm{~g} / 24 \mathrm{hr}$ two years later. Paradoxically the lesion in this patient's repeat biopsy was considered to have progressed from a classification of group 1 to group 2 over the same period.

The group 3 patient had repeated gross haematuria, a maximum recorded proteinuria of $2 \mathrm{~g} / 24 \mathrm{hr}$, and gave a history of sore throat and haematuria two and a half years before biopsy. The clinical lesion at that time was suggestive of an acute glomerulonephritis but biopsy was not performed. There was no evidence of renal insufficiency.

All three patients in group 4 had gross haematuria, two with red cell casts. The patient with acute diffuse proliferative glomerulonephritis has already been discussed. One case of membrano-proliferative glomerulonephritis had $1.5 \mathrm{~g}$ protein per 24 hours, whilst the other showed a progression of proteinuria from $<0.5 \mathrm{~g} / 24 \mathrm{hr}$ to $0.9 \mathrm{~g} / 24 \mathrm{hr}$ in a period of 14 months. A history of numerous upper respiratory tract infections was obtained from the former patient. Two years before biopsy, one of these episodes was complicated by gross haematuria. Later, haematuria developed four days after the development of peritonsillar abscess and it has been recurrent since then.

In general the degree of proteinuria was greater in the patients with the more severe renal lesions. However, the finding of proteinuria in association with haematuria is not necessarily an indication of severe renal disease. In groups 1 and $2,33 \%$ of the patients had both haematuria and proteinuria greater than $0.5 \mathrm{~g} / 24 \mathrm{hr}$, and Rapoport, Deveber, and McLean (1970) reported similar findings in $65 \%$ of 33 patients with focal proliferative nephritis. A level of less than $0.5 \mathrm{~g}$ of protein daily associated with primary haematuria was excreted by two of nine patients showing the severe histological lesions of chronic glomerulonephritis or active proliferative glomerulonephritis (Hendler et al, 1972). In one of the patients in our study repeat biopsy showed a deterioration according to histological grading (from grade 1 to grade 2) but the level of proteinuria had decreased. Renal biopsy remains the only way to determine accurately the degree of morphological involvement of the glomerulus and only after longterm follow-up will the significance of the variety of glomerular lesions be fully appreciated.

Electron microscopy studies in haematuria have previously demonstrated various changes-a focal increase in basement membrane material in axial zones and a variability of basement membrane thickness from loop to loop (Lannigan and Insley, 1965; Singer, Hill, Rosenberg, Marshall, and Swenson, 1968; Glasgow et al, 1970). Lannigan and Insley also described electron-dense material considered to resemble fibrinoid closely applied to the outer side of the basement membrane, in Bowman's 
space, and in the axial zone closely applied to the inner surface of the basement membrane. Hendler et al (1972) found mesangial osmiophilic deposits in one patient, and subepithelial humps in two patients with active proliferative glomerulonephritis. Humps were also seen in six of 31 patients with recurrent haematuria and electron-dense deposits were noted on the endothelial aspect of the basement membrane (Singer et al, 1968). The most common changes observed in this study were variation in membrane diameter, particularly thinning and alterations in density with numerous foci of pallor and deposits of granular electron-dense material mainly in the mesangial region, but also related to the capillary basement membrane. Large open granular deposits similar to those described here have been seen previously in the congenital nephrotic syndrome (Alexander and Campbell, 1971). Splitting of the lamina densa was a most unusual feature and was extremely marked in the patient in group 3 , where granular densities were present within the area of splitting and multilamination. Red cells were seen in Bowman's space in only one glomerulus and no red cells were found in the process of migration from the capillaries to Bowman's space. It is therefore impossible to decide the significance of the basement membrane changes though it is obviously tempting to consider the areas of very marked thinning of the membrane as causally related to the escape of red cells. The presence of a normal configuration of lamina densa, rara interna and externa, epithelial cell foot processes, and fenestrated endothelium in many areas of thinning may suggest a developmental lesion rather than a degenerative one. The possibility of a relationship between the thin capillary membrane and resolution of damage to the membrane by an immunological lesion must also be considered. Granular electron densities considered to represent antigen/antibody complex deposition were fairly commonly observed in these cases, but only in one case were densities obviously related to membrane splitting which might lead to thinning. The antigenic stimulus to antigen/antibody complex formation and deposition is unknown in patients with haematuria of glomerular origin in the absence of one of the recognized entities such as acute poststreptococcal glomerulonephritis. Nothing can be added here to speculation on the relationship of essential haematuria to poststreptococcal infection as discussed previously (Singer et al, 1968; Glasgow et al, 1970; Rapoport et al, 1970). Only six of the patients in this study gave any history of sore throat or other exciting factor, in keeping with the relative lack of association with upper respiratory tract infection, trauma, or exercise found by Burkholder et al (1969) in their investigation of 237 cases of haematuria, 10 of which were considered due to $\stackrel{0}{\widetilde{0}}$
glomerular disease.

In one patient small tubular structures were seen in the endothelial cell cytoplasm. These are similaro? to the virus-like particles found in glomerularo endothelial cells in systemic lupus erythematosus (Fresco, 1968; Norton, 1969). Grausz, Earley, $\frac{\bar{c}}{\stackrel{5}{ }}$ Stephens, Lee, and Hopper (1970) suggest that such $\stackrel{\varnothing}{\varnothing}$ virus-like particles may be present in the glomerular@ endothelium of nearly all patients with SLE and that the inclusions could be a very early diagnostic. finding that is present years before the appearance $\vec{\omega}$ of clinical and laboratory findings generally con- $-\odot$ sidered necessary for the diagnosis of systemicio lupus erythematosus. They have also been found inis renal biopsy material from a patient with sclero- derma, one with Goodpasture's syndrome (Norton, $\vec{\circ}$ 1969), and one with membranous glomerulo- nephritis (Grausz et al, 1970). Duffy (1969) reported similar tubular myxovirus-like particles in the epithelial cytoplasm of a case of lipoid nephrosis. $\vec{O}$ Whilst these structures have been most frequentlyo observed in kidney biopsy material from patients음 with SLE they have been observed in numerous other? situations in a great variety of disorders by Baringer $\overrightarrow{0}$ (1971). He feels that the unique appearance of these $\omega$ aggregates and their distribution within the endeplasmic reticulum of endothelial cells suggests the they may represent a common cellular reaction to variety of injuries. The suggestion of a possible diagnosis of SLE in this patient with haematuria is $\frac{Q}{\varnothing}$ of interest in view of the documentation later in her history of the haematuria becoming so severe $\overrightarrow{\vec{B}}$ during pregnancy that this had to be terminated. $\exists$ Serum complement was normal.

Polykaryocytosis has been discussed fully by Spear, Slusser, Schulman, and Alexander (1971) in their discussion of cystinosis and has been previously:reported in Waldenstrom's macroglobulinaemia 3 . (Argani and Kipkie, 1964), and Goodpasture's syndrome (Pirani and Salinas-Madrigal, 1968; Proskey, Weatherbee, Easterling, Green, and Weller,을 1970). The pathogenesis of polykaryocytosis in the case of focal glomerulonephritis reported here is unknown.

The position of renal biopsy in the investigation of 0 essential haematuria is a point of considerablen disagreement. There are those who would advocate N renal biopsy for all cases of essential haematuria as ${ }_{\sigma}^{\omega}$ they would for all cases of unexplained renal disease, whilst others feel that little is gained and the com- $\frac{\text { C }}{\Phi}$ plications though infrequent may be very severe. $\cong$ In the majority of cases of essential haematuria little information may be gained from biopsy, but there ${ }_{0}^{-}$ remains the fact that renal biopsy is the only way to determine accurately the degree of morphological ${ }_{\mathbb{C}}^{\stackrel{?}{Q}}$ 
involvement of the glomerulus. It is the only way to rule out a more severe variety of renal disease such as membranoproliferative, latent, or chronic glomerulonephritis, and to determine the true prognosis in these cases after full documentation and long-term follow up. Burkholder et al (1969) point out that often these patients want to have biopsies performed to allay suspicion and fear of cancer or progressive renal disease.

Very sincere thanks are due to Dr B. M. Churchill and Dr E. L. Atkins who performed the renal biopsies on these patients, and to Dr L. McLeod, Dr H. Mandin, and Dr M. Davidman for clinical documentation and permission to carry out the investigations on their patients.

\section{References}

Alexander, F., and Campbell, W. A. B. (1971). Congenital nephrotic syndrome and renal vein thrombosis in infancy. J. clin. Path., 24, 27-40.

Alport, A. C. (1927). Hereditary familial congenital haemorrhagic nephritis. Brit. med. J., 1, 504-506.

Argani, I., and Kipkie, G. F. (1964). Macroglobulinemic nephropathy: acute renal failure in macroglobulinemia of Waldenstrom. Amer. J. Med., 36, 151-157.

Baringer, J. R. (1971). Tubular aggregates in endoplasmic reticulum in Herpes-Simplex encephalitis. New Engl. J. Med., 285, 943-945.

Benoit, F. L., Rulon, D. B., Theil, G. B., Doolan, P. D., and Watten, R. H. (1964). Goodpasture's syndrome: a clinico-pathologic entity. Amer. J. Med., 37, 424-444.

Burkholder, G. V., Dotin, L. N., Thomason, W. B., and Beach, P. D. (1969). Unexplained haematuria. J. Amer. med. Ass., 210, 1729-1733.

Duffy, J. L. (1969). Myxovirus-like particles in lipoid nephrosis. New Engl. J. Med., 281, 562-563.

Fresco, R. (1968). Tubular (myxovirus-like) structures in glomerular deposits from a case of lupus nephritis. Fed. Proc., 27, 246.

Glasgow, E. F., Moncrieff, M. W., and White, R. H. R. (1970). Symptomless haematuria in childhood. Brit. med. J., 2, 687-692.

Grace, S. G., Suki, W. N., Spjut, H. J., Eknoyan, G., and MartinezMaldonado, M. (1970). Hereditary nephritis in the negro. Arch. intern. Med., 125, 451-461.
Grausz, H., Earley, L. E., Stephens, B. G., Lee, J. C., and Hopper, J. (1970). Diagnostic import of virus-like particles in the glomerular endothelium of patients with systemic lupus erythematosus. New Engl. J. Med., 283, 506-511.

Habib, R., and Kleinknecht, C. (1971). The primary nephrotic syndrome of childhood: classification and clinicopathologic study of 406 cases. Path. Ann., 6, 417-474.

Hendler, E. D., Kashgarian, M., and Hayslett, J. P. (1972). Clinicopathological correlations of primary haematuria. Lancet, 1, 458-463.

Heptinstall, R. H. (1966). Pathology of the Kidney, pp. 315-333. Little, Brown, Boston.

Heptinstall, R. H., and Joekes, A. M. (1959). Focal glomerulonephritis: a study based on renal biopsies. Quart. J. Med., 28, 329-346.

Herdson, P. B., Jennings, R. B., and Earle, D. P. (1966). Glomerular fine structure in post-streptococcal acute glomerulonephritis. Arch. Path., 81, 117-128.

Kimmelstiel, P., Kim, O. J., and Beres, J. (1962). Studies on renal biopsy specimens with the aid of the electron microscope. II. Glomerulonephritis and glomerulonephrosis. Amer. J. clin. Path., 38, 280-296.

Lannigan, R., and Insley, J. (1965). Light and electron microscope appearances in renal biopsy material from cases of recurrent haematuria in children. J. clin. Path., 18, 178-187.

McCluskey, R. T. (1970). Lupus nephritis. Path. Ann., 5, 125-144.

Norton, W. L. (1969). Endothelial inclusions in active lesions of systemic lupus erythematosus. J. Lab. clin. Med., 74, 369-379.

Pirani, C. L., and Salinas-Madrigal, L. (1968). Evaluation of percutaneous renal biopsy. Path. Ann., 3, 273.

Proskey, A. J., Weatherbee, L., Easterling, R. E., Greene, J. A., and Weller, J. M. (1970). Goodpasture's syndrome: a report of five cases and review of the literature. Amer. J. Med., 48, 162-173.

Rapoport, A., Davidson, D. A., Deveber, G. A., and Ranking, G. N., McLean, C. R. (1970). Idiopathic focal proliferative nephritis associated with persistent haematuria and normal renal function. Ann. intern. Med., 73, 921-928.

Seymour, A. E., Spargo, B. H., and Penksa, R. (1971). Contributions. of renal biopsy studies to the understanding of disease. Amer. J. Path., 65, 550-588.

Singer, D. B., Hill, L. L., Rosenberg, H. S., Marshall, J., and Swenson R. (1968). Recurrent hematuria in childhood. New Engl. J. Med., 279, 7-12.

Spear, G. S., Slusser, R. J., Schulman, J. D., and Alexander, F. (1971). Polykaryocytosis of the visceral glomerular epithelium in cystinosis with description of an unusual clinical variant. Johns Hopkins med. J., 129, 83-99.

Volhard, F., and Fahr, T. (1914). Die Brightsche Nierenkrankheit. Springer, Berlin. 